UDC 316.33

LBC 60.5

\title{
VISUALIZATION OF HISTORICAL MEMORY IN NETWORK SOCIETY: METHODOLOGICAL GROUNDS FOR RESEARCH ${ }^{1}$
}

\author{
Daniil A. Anikin \\ Saratov State University, Saratov, Russian Federation
}

\begin{abstract}
The article analyzes methodological approaches to the study of visual images of historical memory, reveals the distinction of performative and representational paradigms in historical knowledge. The specifics of the performative paradigm which is close methodologically to the actor-network approach is to reveal the act of performance as a complex interaction of historical reality with modern artifacts that operates as ways of conveying information about the past. Emerging visual image (a monument, a symbol or meme) is the articulation of tangible and intangible structures that can be subjected to cultural encoding or decoding explaining the polysemy of visual historical images.

According to the author, the study of the visual practices of fixing the past is still insufficiently explored in social-philosophical discourse, which makes it necessary to identify patterns of transformation of visual images in the context of General laws of social dynamics and formation of network society. The analysis of the relationship of the visualization of historical memory with the modern trends of social development, primarily with the transformation of network communications in the dominant type of social interaction is relevant. This process leads to the fact that historical memory becomes the subject of competing strategies of political actors and the way to achieve the set goals becomes not only the creation of new images but also the attribution of new meanings to the existing ones. Symbolic competition takes place at the level of interpretations circulating in society, visual images, attributing or denying certain values.

The main trends of the network society contributing to the actualization of visual images as integral elements of commemorative practices are pluralization, polymorphizaion and virtualization. Pluralization is determined by the multiplicity of political actors that use visual images as tools of appropriating symbolic capital that circulates in the society. Polimorphization involves the impossibility of the only strategy of interpretation. Virtualization is directly related to the emergence and development of virtual communications allowing to transfer the way of networking in the basic principle of the collective solidarity and the starting point of processes of self-identification.
\end{abstract}

Key words: historical memory, visualization, practices, network society, network.

УДК 316.33

ББК 60.5

\section{ВИЗУАЛИЗАЦИЯ ИСТОРИЧЕСКОЙ ПАМЯТИ В СЕТЕВОМ ОБЩЕСТВЕ: МЕТОДОЛОГИЧЕСКИЕ ОСНОВАНИЯ ИССЛЕДОВАНИЯ ${ }^{1}$}

\author{
Даниил Александрович Аникин \\ Саратовский национальный исследовательский государственный университет им. Н.Г. Чернышевского, \\ г. Саратов, Российская Федерация
}

\footnotetext{
ㄱ Аннотация. В статье анализируются методологические подходы к изучению визуальных образов исто궁 рической памяти, раскрывается различие перформативной и репрезентационной парадигм в историческом ¿ познании. Специфика перформативной парадигмы, тесно пересекающейся в методологическом смысле с - акторно-сетевым подходом, заключается в понимании самого акта представления как сложного взаимодействия исторической реальности с современными артефактами, выступающими способами передачи информации о прошлом. Вновь возникающий визуальный образ (памятник, символ или мем) является сочленением материальных и нематериальных структур, которые могут подвергаться культурному кодированию или (?) декодированию, чем объясняется многозначность визуального исторического образа.
} 
По мнению автора, визуальные практики закрепления прошлого еще недостаточно изучены в социально-философском дискурсе, что делает необходимым выявление закономерностей трансформации визуальных образов в контексте общих закономерностей социальной динамики и становления сетевого общества. Актуальным является анализ взаимосвязи визуализации исторической памяти с современными тенденциями социального развития, прежде всего с превращением сетевых коммуникаций в господствующий тип социального взаимодействия. Этот процесс приводит к тому, что историческая память становится предметом конкурирующих стратегий со стороны политических акторов, а способом достижения заданных целей становится не только создание новых образов, но и придание новых смыслов уже имеющимся. Символическая конкуренция разворачивается на уровне интерпретации циркулирующих в обществе визуальных образов, приписывании или отрицании определенных значений.

Основными тенденциями сетевого общества, способствующими актуализации визуальных образов в качестве неотъемлемых элементов коммеморативных практик, стоит считать плюрализацию, полиморфизацию и виртуализацию. Плюрализация определяется множественностью политических акторов, использующих визуальные образы в качестве средств присвоения символического капитала, циркулирующего в обществе. Полиморфизация заключается в принципиальной невозможности единственной стратегии интерпретации. Виртуализация напрямую связана с возникновением и развитием виртуальных коммуникаций, позволяющих перевести способ сетевого взаимодействия в базовый принцип обеспечения коллективной солидарности и исходную точку процессов самоидентификации.

Ключевые слова: историческая память, визуализация, практики, сетевое общество, сеть.

Историческая память как совокупность перформативных практик, выполняемых и видоизменяемых в процессе выполнения отдельными индивидами и сообществами, подразумевает потребность в определенном соотношении между онтологически недоступным прошлым и его современными репрезентациями, которые дают возможность установить такое соотношение. Если в рамках структуралистского подхода репрезентации сводились к статической совокупности определенных знаков, отсылающих к персонажам или событиям исторической реальности, то в современных социальных науках большее значение уделяется процессуальности и праксиологичности образов прошлого. Репрезентация в своем дословном значении являет собой феномен осовременивания или актуализации прошлого, но при этом важно понимать, что процесс сочленения прошлого и настоящего не имеет характера «насилия» по отношению к историческим фактам, поскольку элементы исторической реальности обладают способностью не соответствовать навязываемым им значениям. Иначе говоря, процесс конструирования образов прошлого не является произвольным, а подчиняется определенным закономерностям, обязательно учитывающим не только потребности в консолидации или конфронтации современного сообщества, но и этико-эстетические параметры создаваемых образов, а также обязательный аспект гносеологической вероятности.
Э. Пикеринг проводит различие между репрезентационной и перформативной парадигмами в историческом познании, указывая, что ограниченность репрезентационной парадигмы основывается на отнесении возможности репрезентации исключительно к человеческим существам, в то время как перформативная обязательно подразумевает наличие артефактов и их соучастие в процессе конструирования исторической реальности [13, p. 413-414]. Нетрудно заметить, что перформативная парадигма в данном случае оказывается тесно связана с акторно-сетевым подходом, также делающим упор на включение неодушевленных предметов (артефактов) в разряд акторов, формирующих контуры социальной практики. Как справедливо отмечает Э. Доманска, «это не означает, что такое понимание действия приписывает интенциональность нечеловеческим существам или предлагает возрождение анимизма, заменяет субъекта-деятеля его нечеловеческими аналогами... исследователи просто привлекают наше внимание к тому, что изменения в реальности происходят благодаря кооперации разных акторов» [5, с. 233].

Именно в условиях изменения исследовательской оптики, когда внимание переключается с текстовых конструкций на социальные процедуры и механизмы воспроизводства разделяемых обществом смыслов, большое значение приобретают визуальные обра- 
зы прошлого, их включенность в социальные практики. По мере развития социальной антропологии и распространения ее исследований на феномены современного общества внимание исследователей все чаще захватывают способы и формы визуальной репрезентации социальной реальности. При этом следует отметить, что в сфере исследований исторической памяти анализ визуальных практик пока остается на уровне отдельных «кейсов». Еще П. Нора в своей фундаментальной работе «Места памяти» посвятил несколько отдельных очерков тем архитектурным памятникам и визуальным образам, которые продолжают воспроизводиться в современном французском обществе, не только воплощая неразрывную связь прошлого и настоящего, но и активно включаясь в коммеморативные практики [8, с. 152-180]. В работах целого ряда отечественных авторов делались попытки связать визуальные методы исследования с изучением отдельных мест «памяти» [4, c. 97-203].

Вместе с тем имеющиеся исследования не ставят принципиальный для социально-философского анализа вопрос о природе визуальных репрезентаций прошлого, причинах и формах их взрывного распространения в современном обществе. Важным для философской постановки вопроса представляется анализ тех теоретических концепций, использование которых позволяет определить не только истоки репрезентативности исторической памяти, но и выявить специфику форм репрезентаций в условиях становления сетевых социальных структур.

Одним из первых к анализу визуальных образов обратился немецкий исследователь В. Беньямин. В одной из своих ранних работ он констатирует, что создание репродукционной техники переворачивает всю историю визуального образа, поскольку делает возможным соучастие практически каждого в появлении и тиражировании новых образов. «С развитием репродукционной техники изменилось восприятие великих произведений искусства. На них уже нельзя смотреть как на произведения отдельных людей; они стали коллективными творениями, настолько мощными, что для того, чтобы их усвоить, их необходимо уменьшить» [2, с. 14].
Эта идея отчетливее концептуализируется В. Беньямином в работе «Произведение искусства в эпоху технической воспроизводимости», где он делает акцент на том, что любой образ становится продуктом технического производства, в силу чего исчезает уникальность и появляется тиражируемость. В этом он видит неожиданное, но вполне логичное следствие формирования массового общества, в котором исчезает прерогатива как на абсолютную власть, так и на уникальность художественного дара. Характерно, что немецкий философ отмечает важность происходящих изменений для процесса взаимодействия общества со своим прошлым: «Репродукционная техника... выводит репродуцируемый предмет из сферы традиции... А позволяя репродукции приближаться к воспринимающему ее человеку, где бы он ни находился, она актуализирует репродуцируемый предмет» [3, c. 196]. Иначе говоря, именно техника (под которой в первую очередь понимается фотография и кинематограф) размывает казавшиеся незыблемыми линии соотношения между прошлым и настоящим, порождает потребность в постоянной актуализации прошлого.

Идеи В. Беньямина, высказанные еще в 30-е гг., оказались созвучны взглядам канадского социолога М. Маклюэна. Он отмечает, что развитие технологий в $\mathrm{XX}$ в. привело к тому, что именно визуальные образы стали основным инструментом формирования мировоззрения. На смену «Галактики Гуттенберга» пришла новая вселенная образов, в ней действуют свои закономерности, без учета которых невозможны эффективные стратегии управления, воспроизводство привычного образа жизни и способов поведения [7, с. 51]. Сам Маклюэн расценивает происходящие изменения крайне положительно, считая, что происходит восстановление утраченной целостности человека как биологического существа, поскольку совершенствование логической части его сознания (на чем делался упор в письменной культуре) теперь гармонично дополняется развитием образного мышления.

В 60-е гг. возникает понимание того, что пространство визуальных образов становится самостоятельной сферой исследований, подразумевающей собственный набор методов и методологических установок. 
Выведение изучения визуальных образов на уровень антропологического исследования является заслугой американского ученого Маргарет Мид. Она впервые обратила внимание на то, что визуальные способы фиксации образов могут выполнять важную роль в процессе анализа того или иного сообщества [12, p. 11]. Что характерно, для самой исследовательницы видеосъемка и фотографии представали в качестве объективных и беспристрастных инструментов научного разума, направленных на препарирование скрытой от посторонних глаз культурной действительности. Однако развитие визуальной антропологии опровергло тезис о культурной непредвзятости механически фиксируемого образа, причем сразу по двум основным позициям.

Первая позиция обращает внимание на то, что объективом камеры или фотоаппарата управляет оператор, следовательно подбор образов является не беспристрастным процессом научной фиксации, а формой культурно заданной селекции анализируемой ситуации, поскольку взгляд оператора нацелен на те паттерны культурной реальности, которые привлекают его внимание. Вторая позиция акцентирует внимание на том факте, что один и тот же визуальный образ, будучи помещенным в различные контексты, может приобретать противоположные значения. По словам отечественных исследователей П.В. Романова и Е.Р. Ярской-Смирновой, «следует говорить не только о различиях в понимании смысла текста автором и аудиторией, но и об эффекте взаимовлияний текста и контекста социальных, экономических, политических и культурных условий производства визуального текста, его распространения и восприятия» [11, c. 14].

Примером, иллюстрирующим многозначность способов прочтения визуального образа, является история знаменитой фотографии Д. Уайденера «Tank Man» («Неизвестный бунтарь»). Эта фотография, сделанная из окна пекинской гостиницы, запечатлела оставшегося неизвестным китайца, который преградил путь танковой колонне, вступающей на площадь Тяньаньмэнь во время студенческих выступлений 1989 года [14, p. 34]. Для западноевропейской публики доминирующей интер- претацией этого образа стала готовность китайского народа к демократическим преобразованиям, в то время как официальная китайская позиция заключалась в подчеркивании слабости и малочисленности протестных настроений. Такие противоречивые суждения базировались на одном и том же визуальном образе.

Наиболее развернутый подход к изучению визуальных образов предложил П. Штомпка. С его точки зрения, визуализация представляет собой процесс создания образов, которые с максимальной степенью эффективности способны воздействовать на воображение потребителя, трансформируя и (или) символически перекодируя его социальные практики. Именно поэтому визуализация становится одним из наиболее действенных способов репрезентации смыслов и идей, причем особую актуальность визуальные репрезентации приобретают в последние десятилетия [10, с. 7].

Можно выявить определенную амбивалентность образов, которая заключается в том, что они могут выступать как методом, так и объектом исследования. Снятый о каком-нибудь историческом событии фильм или растиражированный в социальных сетях исторический мем могут быть помещены в контекст репрезентаций - как в статическом, так и в динамическом смысле. С одной стороны, они будут являться элементами более сложной и многообразной системы визуальных репрезентаций, функционирующих в обществе на данном этапе его развития, а с другой будут вписаны в цепочку интерпретаций события прошлого, выступая как логическим следствием предшествующих образов, так и источником для продуцирования новых. Знаменитый фильм «Александр Невский», снятый С. Эйзенштейном в 1939 г., не только демонстрирует визуализацию определенных представлений об историческом событии, но и вписывается в общий контекст советской исторической политики [9, с. 303-394].

Следует напомнить, что историческая память - это не набор стандартных исторических образов, а изменчивый и плюралистический процесс их комбинирования и конфигурирования в интересах определенных социальных общностей. Основной целевой аудиторией вос- 
производства исторической памяти является молодежь, поэтому потребность в наглядности и яркости транслируемых образов неразрывно связана с самими механизмами передачи исторического опыта, особенно в условиях ограниченности письменной коммуникации.

Я. Ассман отмечает, что еще в архаических обществах возникла потребность в визуализации определенных образов, отсылающих к первоистокам существования социальной общности [1, с. 180-182]. Ограниченность письменной коммуникации, точнее говоря, ее замкнутость в пределах жестко иерархизированной интеллектуальной элиты приводила к необходимости использования визуальных образов для трансляции исторических образов. При этом возникала любопытная двойственность «монументального дискурса», проявляющего себя как в социальном мире, так и в мифологическом пространстве. Как пишет сам Я. Ассман, «государство - это не только установление, обеспечивающее мир, порядок и справедливость, но тем самым одновременно и установление, дающее возможность бессмертия или по меньшей мере посмертного продолжения» [1, с. 184]. Таким образом, визуализация должна была не просто отразить актуальную политическую значимость тех или иных персонажей или событий, а она являлась способом установления связи между имманентным и трансцендентным пропуском в неизменный мир мифологических архетипов.

Монументальность архитектурных образов служила формой выражения и одновременно способом поддержания культурной памяти, отсылающей к тем основам социального порядка, которые постулируются в качестве вечных и неизменных. По сути это являлось визуализацией этиологического мифа, устанавливающего точку отсчета существования определенного сообщества. В этом смысле египетские пирамиды являются такой же формой визуального закрепления культурной памяти для египетского общества, как и мавзолей В.И. Ленина - для советского народа.

Схожее отношение к визуальным образам можно наблюдать и в средневековом обществе, во многом схожем с культурами классической древности: сословное деление общества, безусловная прерогатива интеллектуаль- ной элиты на использование письменной коммуникации, низкий темп социальных изменений. В сложившихся условиях производство образов прошлого также подчинялось закономерностям «монументального дискурса», поскольку каждый визуальный образ отсылал к образцу, источнику, устанавливал взаимосвязь между единичным изображением и вневременным оригиналом. Применительно к средневековой культуре эта мысль может быть прояснена на примере готического собора, который визуализировал идею феодальной иерархии, демонстрируя ту же устремленность к небесам (параллельно с разницей уровней), которой проникнута теология Августина Блаженного [6, с. 98-99].

Источником интенсификации визуальных образов в развитии современной культуры П. Штомпка называет четыре основных процесса:

1. Процесс цивилизационного и технического развития, приводящий к постепенному замещению природного мира совокупностью созданных человеком реальностей, отличающихся различной степенью симулятивности. По сути возникновение инструментария, способного не просто воспроизводить, а тиражировать визуальные образы, становится предпосылкой их активного распространения.

2. Возникновение и активное развитие городского образа жизни, который приводит к дифференциации визуальных образов. Горожанин, оторванный от относительно обособленных традиций воспроизводства определенных символов, свойственных аграрным сообществам, становится восприимчив к избыточности визуальности.

3. Коммерциализация, вызывающая к жизни потребность в визуальной привлекательности потребляемого продукта, под которым может пониматься не только конкретный предмет, но и совокупность определенных идей или точек зрения. Память в этом смысле также является предметом коммерциализации, поскольку подразумевает возможность выстраивания целой индустрии, ориентированной на производство памятных сувениров, туристических маршрутов и других форм репрезентации прошлого.

4. Зарождение потребительского общества, что означает сосредоточенность на фор- 
мировании все новых и новых зрительских впечатлений. Характерно, что в этот процесс вовлекаются в той или иной степени все члены сообщества, поэтому создание, распространение и обмен визуальными образами становится одной из основных форм социальной коммуникации [10, с. 13].

Но если для М. Маклюэна и П. Штомпки основной причиной происходящих изменений являются технологические достижения, позволяющие обеспечить бесперебойное тиражирование визуальных образов, то социальный аспект происходящих процессов оказывается рассмотрен в меньшей степени. М. Маклюэн, будучи сторонником технологического детерминизма, по сути сводит социальные изменения к следствиям технологического переворота в сфере массовых коммуникаций. П. Штомпка более аккуратно апеллирует к теории «общества потребления» Ж. Бодрийара, но при этом не акцентирует внимания, в силу своей сосредоточенности на визуальных методах исследования, на тех социальных процессах, которые служат естественным условием неуклонного роста визуальных образов и обретения ими подавляющего значения в современных перформативных практиках.

К основным механизмам трансформации практик визуализации исторической памяти в сетевом обществе можно отнести плюрализацию, полиморфизацию и виртуализацию.

В условиях распада национальных общностей происходит плюрализачия социального порядка, естественным образом отражающаяся на механизмах репрезентации исторической памяти, в том числе и на трансформации стратегий визуальной репрезентации. Сложившиеся в эпоху существования национальных государств стратегии подвергаются переконфигурированию, в результате чего возникает феномен семиотической полисемантичности. Визуальные образы лишаются привычных коннотаций, взамен приобретая новые значения, зачастую диктуемые ситуативным порядком социальных взаимодействий. Значения визуальных образов перестают опираться на относительно устойчивые интерпретативные техники, поскольку доступ к включению образов в перформативные практики получает достаточно широкий круг акторов. Разумеется, расширение круга потенциальных акторов не обозначает превращение визуализации прошлого в симулятивный механизм свободного обращения знаков (как это в более широком смысле предсказывал Ж. Бодрийар), поскольку потенциальная бесконечность участников сетевого взаимодействия ограничивается наличием символических и материальных ресурсов обеспечения складываемых и поддерживаемых практик.

Сетевой характер формирующегося социального пространства приводит к потребности ориентации создаваемых и транслируемых символов на определенный набор социальных и политических акторов, который не имеет субстанциальной основы, то есть подвергается периодическому модерированию. Образы подвергаются полиморфизации, то есть приобретают неопределенность и амбивалентность, позволяющую использовать их в практиках легитимации различных социальных и политических позиций.

Наконец, виртуализащия визуальных практик исторической памяти напрямую связывается с распространением интернет-технологий, что позволяет раздвинуть границы «воображаемых сообществ», создавая виртуальные точки пересечения интересов и тем самым добиваясь временной фиксации тех или иных способов отношения к прошлому. Легкость тиражирования визуальных образов в сетевом пространстве и их неопределенный, легко поддающийся трансформации статус способствует размыванию границ социальной идентичности, которая приобретает пластичность и подвижность. Соотношение с определенным историческим прошлым строится на полиморфных визуальных образах, что задает достаточно широкие пределы вариативности. Эти образы, с одной стороны, задают вектор легитимации существующей позиции в сетевом пространстве, а с другой - обеспечивают степень свободы в подборе и конфигурировании отдельных образов.

\section{ПРИМЕЧАНИЕ}

1 Статья выполнена в рамках гранта Президента РФ МК-2596.2017.6 «Политика памяти в сетевом обществе: символические ресурсы и социальные риски» и гранта РФФИ 16-33-01019 «Государственная политика памяти в Российской Федерации: философские основания и стратегии реализации». 


\section{СПИСОК ЛИТЕРАТУРЫ}

1. Ассман, Я. Культурная память. Письмо, память о прошлом и политическая идентичность в высоких культурах древности / Я. Ассман. - М. : Языки славянской культуры, 2004. - 368 с.

2. Беньямин, В. Краткая история фотографии / В. Беньямин. - М. : Ad Marginem, 2015. - 143 c.

3. Беньямин, В. Учение о подобии. Медиаэстетические произведения / В. Беньямин. - М. : РГГУ, 2012. -288 c.

4. Визуальная антропология: городские карты памяти. - М. : Вариант, 2009. -312 с.

5. Доманска, Э. Перформативный поворот в современном гуманитарном знании / Э. Доманска // Способы постижения прошлого: Методология и теория исторической науки. - М. : Канон +, 2011.C. 226-236.

6. Ле Гофф, Ж. История и память / Ж. Ле Гофф. - М. : РОССПЭН, 2013. - 303 с.

7. Маклюэн, М. Галактика Гутенберга. Становление человека печатающего / М. Маклюэн. - М. : Академический Проект ; Гаудеамус, 2013. - 412 с.

8. Франция-Память. - СПб. : Изд-во СанктПетерб. ун-та, 1999. - 298 с.

9. Шенк, Ф. Александр Невский в русской культурной памяти / Ф. Шенк. - М. : Новое литературное обозрение, 2007. - 592 с.

10. Штомпка, П. Визуальная социология / П. Штомпка. - М. : Логос, 2007. - 168 с.

11. Ярская-Смирнова, Е. Р. Взгляды и образы: методология, анализ, практика / Е. Р. Ярская-Смирнова, П. В. Романов // Визуальная антропология: настройка оптики. - М. : Вариант, 2009. - С. 7-16.

12. Chalfen, R. Combining the Applied, the Visual and the Medical: Patients Teaching Physicians with Visual Narratives / R. Chalfen, M. Rich. - New York : Berghahn Books, 2007. - 180 p.

13. Pickering, A. After Representation: Science Studies in the Performative Idiom / A. Pickering // Proceedings of the Biennial Meeting of the Philosophy of Science Association. - 1994. - Vol. 2. - P. 413-419.

14. The Tiananmen Papers, The Chinese Leadership's Decision to Use Force Against their Own People - In their Own Words / Andrew J. Nathan and Perry Link (eds.). - New York : Little, Brown \& Co., 2001. -212 p.

\section{REFERENCES}

1. Assman J. Kulturnaya pamyat. Pismo, pamyat o proshlom $i$ politicheskaya identichnost $v$ vysokikh kulturakh drevnosti [Cultural Memory. The Letter, the Memory of the Past and Political Identity in the High Cultures of Antiquity]. Moscow, Yazyki slavyanskoy kultury Publ., 2004. 368 p.

2. Benjamin W. Kratkaya istoriya fotografii [Short History of the Photo]. Moscow, Ad Marginem Publ., 2015. 143 p.

3. Benjamin W. Uchenie o podobii. Mediaesteticheskie proizvedeniya [The Doctrine about Similarity. Media Esthetic Works]. Moscow, RGGU Publ., 2012.288 p.

4. Vizualnaya antropologiya: gorodskie karty pamyati [Visual Anthropology: City Memory Cards]. Moscow, Variant Publ., 2009. 312 p.

5. Domanska E. Performativnyy povorot $\mathrm{v}$ sovremennom gumanitarnom znanii [Performatory Turn in Modern Humanities]. Sposoby postizheniya proshlogo: Metodologiya i teoriya istoricheskoy nauki [Ways of Comprehension of the Past: Methodology and Theory of Historical Science]. Moscow, Canon+ Publ., 2012, pp. 226-236.

6. Le Goff J. Istoriya $i$ pamyat [History and Memory]. Moscow, ROSSPEN Publ., 2013. 303 p.

7. McLuhan M. Galaktika Gutenberga. Stanovlenie cheloveka pechatayushchego [Gutenberg's Galaxy. Formation of the Printing Person]. Moscow, Academic Project Publ., Gaudeamus Publ., 2013. 412 p.

8. Frantsiya-Pamyat [France-Memory]. Saint Petersburg, Izd-vo Sankt-Peterb. un-ta, 1999. 298 p.

9. Schenk F. Aleksandr Nevskiy v russkoy kulturnoy pamyati [Alexander Nevsky in the Russian Cultural Memory]. Moscow, Novoe literaturnoe obozrenie Publ., 2007. 592 p.

10. Sztompka P. Vizualnaya sotsiologiya [Visual Sociology]. Moscow, Logos Publ., 2007. 168 p.

11. Yarskaya-Smirnova E.R., Romanov P.V. Vzglyady i obrazy: metodologiya, analiz, praktika [Views and Images: Methodology, Analysis, Practice]. Vizualnaya antropologiya: nastroyka optiki [Visual Anthropology: Control of Optics]. Moscow, Variant Publ., 2009, pp. 7-16.

12. Chalfen R., Rich M. Combining the Applied, the Visual and the Medical: Patients Teaching Physicians with Visual Narratives. New York, Berghahn Books, 2007. 180 p.

13. Pickering A. After Representation: Science Studies in the Performative Idiom. Proceedings of the Biennial Meeting of the Philosophy of Science Association, 1994, vol. 2, pp. 413-419.

14. Nathan A.J., Link P., eds. The Tiananmen Papers, The Chinese Leadership's Decision to Use Force Against their Own People - In their Own Words. New York, Little, Brown \& Co., 2001. 212 p. 


\section{Information about the Author}

Daniil A. Anikin, Candidate of Philosophical Sciences, Associate Professor, Department of Theoretical and Social Philosophy, Saratov State University, Astrakhanskaya St., 83, 410012 Saratov, Russian Federation, dandee@list.ru.

\section{Информация об авторе}

Даниил Александрович Аникин, кандидат философских наук, доцент кафедры теоретической и социальной философии, Саратовский национальный исследовательский государственный университет им. Н.Г. Чернышевского, ул. Астраханская, 83, 410012 г. Саратов, Российская Федерация, dandee@list.ru. 